\title{
ANALISIS PENGARUH CITRA PRODUK, HARGA JUAL DAN DESAIN KEMASAN TERHADAP KEPUTUSAN PEMBELIAN VCO DI APOTEK MATAHARI
}

\author{
Ovalina Sylvia Br. Ginting ${ }^{1}$, Ahmad Arif Affandi ${ }^{2 *}$ \\ 1,2,Prodi Farmasi, Fakultas Ilmu Kesehatan, Universitas Haji Sumatera Utara, Medan, Indonesia. \\ Email: ahmadarif.afandi2630@ gmail.com \\ *corresponding author
}

\begin{abstract}
Abstrak
Tujuan penelitian ini untuk mengetahui pengaruh citra produk, harga jual produk dan desain kemasan produk terhadap keputusan pembelian obat herbal VCO. Jenis penelitian yang dilakukan adalah berupa studi kasus dengan menggunakan data primer. Populasi dalam penelitian ini adalah pasien Apotek Matahari yang jumlahnya tak terbatas dengan jumlah sampel sebanyak 69 responden. Pengambilan sampel menggunakan teknik non probability sampling. Data diperoleh dari hasil wawancara dan pembagian kuesioner. Analisis data menggunakan regresi berganda. Berdasarkan hasil analisis, pengujian secara parsial dengan menggunakan uji $\mathrm{t}$ menunjukkan bahwa variabel citra produk dan desain kemasan produk berpengaruh signifikan terhadap keputusan pembelian Obat Herbal VCO sedangkan untuk harga jual produk tidak berpengaruh signifikan terhadap keputusan pembelian Obat Herbal VCO. Pengujian secara simultan dengan menggunakan uji $\mathrm{F}$ menunjukkan bahwa variabel citra produk, harga jual produk serta desain kemasan produk secara bersama-sama berpengaruh signifikan terhadap keputusan pembelian Obat Herbal VCO.
\end{abstract}

Kata kunci: Citra Produk, Harga Jual Produk, Desain Kemasan, Keputusan Pembelian.

\begin{abstract}
The aims of this study were to know the partial and simultantinfluence of product image, product price and packaging to purchase decision of herbal medicine VCO. The design of this study was a case study using the primary data. The population of this study were the consumers of Matahari Pharmacy. The sample size was 69 respondents.The sample was chosen using non-probability sampling. Data was collected by interviewing and distributing questionairs. The data was analysed using multiple linear regression. The research found that the product image and product packaginghad a significant influence to the purchase decision of herbal medicine VCO, while the product price had no significant influence to the purchase decision of herbal medicine VCO. Simultaneously, product image, product price and product packaginghad significant influence to purchase decision of herbal medicine VCO.
\end{abstract}

Key words: product image, product price, product packaging, purcharse decision 


\section{PENDAHULUAN}

Minyak Kelapa Murni (Virgin Coconut Oil atau VCO) merupakan produk olahan asli Indonesia yang terbuat dari daging kelapa segar. Minyak kelapa murni (VCO) mempunyai banyak manfaat terutama dalam bidang kesehatan diantaranya, merupakan anti bakteri, menjaga kesehatan jantung, membantu mencegah penyakit osteoporosis, diabetes, serta dapat menurunkan berat badan dan memelihara kesehatan kulit (Lucida dkk., 2008).Kandungan antioksidan di dalam VCO sangat tinggi seperti tokoferol yang berfungsi untuk mencegah penuaan dini dan menjaga vitalitas tubuh (Setiaji dan Surip, 2006). Di samping itu VCO pun efektif dan aman digunakan sebagai moisturizer pada kulit sehingga dapat meningkatkan hidratasi kulit (Lucida dkk., 2008).

Perkembangan bisnis pada era globalisasi ini tidak luput dari persaingan yang semakin ketat dalam memasarkan produk dan jasa. Sehingga setiap perusahaan dituntut untuk selalu berusaha keras dalam berinovasi terhadap produk maupun jasanya agar mampu bertahan dari persaingan dan mampu menarik perhatian dari calon konsumen akan produk yang ia tawarkan. Namun hal yang perlu diperhatikan sebelum merancang inovasi, seseorang harus jelas terlebih dahulu segmentasi dan target mana yang akan disasar (Sukotjo, 2007).

Masalah pemasaran hakekatnya tidak hanya diarahkan untuk memuaskan pelanggan melainkan juga ditujukan untuk memengaruhi keputusan pembelian konsumen, sehingga keputusan pembelian konsumen mempunyai suatu momen yang penting dalam aktivitas perusahaan. Oleh karena itulah keputusan pembelian merupakan titik pokok dalam proses pencarian dan evaluasi atas beberapa alternatif yang ada, guna menentukan pembelian yang nyata atas suatu produk (Goenadhi, 2011).

Penerapan strategi pemasaran yang tepat dapat mempengaruhi calon konsumen untuk membuat suatu keputusan pembelian. Keputusan konsumen dalam mengambil keputusan pembelian dipengaruhi oleh akal pemikiran atas informasi pengetahuan yang didapatkan. (Goenadhi, 2011). Perusahaan Obat Herbal VCO merupakan perusahaan yang bergerak di bidang industri obat herbal. Hal ini perlu diperhatikan oleh perusahaan agar perusahaan dapat lebih meningkatkan penjualan serta dapat mengantisipasi persaingan yang semakin ketat dengan perusahaan pesaing lainnya (Graham, 2007).

Adapun faktor-faktor yang mempengaruhi pertimbangan konsumen dalam keputusan pembelian obat herbal VCO adalah citra produk, harga jual produk, dan desain kemasan produk. Ketiga faktor tersebut berpengaruh terhadap keputusan pembelian.

\section{METODE PENELITIAN}

Jenis penelitian yang dilakukan adalah berupa studi kasus dengan menggunakan data primer. Populasi dalam penelitian ini adalah pasien Apotek Matahari yang jumlahnya tak terbatas dengan jumlah sampel sebanyak 69 responden.Penelitian ini dilaksankan dari bulan April- Mei 2021. Pengambilan sampel menggunakan teknik non probability sampling. Data diperoleh dari hasil wawancara dan pembagian kuesioner. Analisis data menggunakan regresi berganda dengan menggukan uji $\mathrm{T}$ untuk menguji kemaknaan koefisien regresi parsial dan Uji F untuk mengetahui sejauh mana variabel bebas berpengarahu secara simultan yang digunakan untuk menjelaskan variabel terikat. 


\section{HASIL DAN PEMBAHASAN}

Berdasarkan perhitungan regresi berganda antara Citra Produk dan Harga Jual Produk terhadap Keputusan Pembelian dengan menggunakan program SPSS, diperoleh hasil sebagai berikut.

\begin{tabular}{|c|c|c|c|c|c|}
\hline \multirow[b]{2}{*}{ Model } & \multicolumn{2}{|c|}{$\begin{array}{c}\text { Unstandardized } \\
\text { Coefficients }\end{array}$} & \multirow{2}{*}{$\begin{array}{c}\begin{array}{c}\text { Standardized } \\
\text { Coefficients }\end{array} \\
\text { Beta }\end{array}$} & \multirow{2}{*}{$\mathbf{T}$} & \multirow{2}{*}{ Sig } \\
\hline & B & $\begin{array}{l}\text { Std. } \\
\text { Error }\end{array}$ & & & \\
\hline $\begin{array}{l}\text { (Constant) } \\
\text { Citra Produk } \\
\text { Harga Jual Produk } \\
\text { Desain Kemasan } \\
\text { Produk }\end{array}$ & $\begin{array}{l}2.002 \\
.298 \\
.010 \\
.200\end{array}$ & $\begin{array}{l}.464 \\
.123 \\
.084 \\
.083\end{array}$ & $\begin{array}{l}.260 \\
.013 \\
.254\end{array}$ & $\begin{array}{c}4.318 \\
2.425 \\
.119 \\
2.419\end{array}$ & $\begin{array}{l}.000 \\
.017 \\
.906 \\
.018\end{array}$ \\
\hline
\end{tabular}

Dapat diketahui signifikansi Citra Produk sebesar 0,017. signifikansi 0,017 lebih kecil dari 0,05 (P value (sig) $0.05(\alpha)$ maka $\mathrm{H}_{\mathrm{a}}$ diterima) dan hipotesis nol ditolak, jadi dapat disimpulkan bahwa variabel Citra Produk berpengaruh signifikan terhadap Keputusan Pembelian. Hal ini dikarenakan responden sebagai pembeli sekaligus konsumen yakin bahwa Obat herbal VCO aman untuk dikonsumsi karena menggunakan bahan alami, di mana dengan bahan alami tersebut maka Obat herbal VCO tidak memberikan efek samping, sehingga aman untuk dikonsumsi dalam jangka panjang. Hal itulah yang menjadikan obat herbal VCO memiliki citra positif di benak konsumen dan kemudian mempengaruhi keputusan pembelian konsumen obat herbal VCO. Citra produkuk ialah sekumpulan asosiasi yang dipersepsikan konsumen terhadap barang/jasa yang meliputi professional, kualitas produk asli atau palsu, berkualitas baik, desain menarik, dan bermanfaat.

Citra produk menjadi salah satu pegangan bagi konsumen dalam mengambil keputusan penting. Contoh : keputusan untuk membeli suatu barang, keputusan untuk menentukan tempat bermalam, keputusan untuk mengkonsumsi makanan dan minuman, pengambilan kursus, sekolah, dan lain- lain. Citra yang baik akan menimbulkan dampak positif bagi produk tersebut, sedangkan citra yang buruk melahirkan dampak negatif dan melemahkan kemampuan produk tersebut dengan produk lain dalam persaingan (David, 1996).

Faktor- faktor yang mempengaruhi citra produk meliputi, keunggulan asosiasi merek, kekuatan asosiasi merek, dan keunikan asosiasi mereka. Produk yang baik dapat menyampaikan makna tambahan tentang jaminan kualitas produk yang memiliki keunikan yang khas, menggambarkan sesuatu mengenai manfaat produk bagi pemakainya, mudah diucapkan, dikenali dan diingat, dan tidak mengandung arti yang buruk di Negara dan bahasa lain, serta dapat menyesuaikan diri (adaptable) dengan produk-produk baru yang mungkin ditambahkan ke dalam lini produk (David, 1997.

Signifikansi harga jual produk sebesar 0.906 .signifikansi 0.906 lebih besar dari 0,05 maka hipotesis nol diterima, jadi dapat disimpulkan harga jual produk tidak berpengaruh signifikan terhadap Keputusan Pembelian. Hal itu dikarenakan harga jual yang ditawarkan obat herbal VCO sesuai dengan manfaat yang diperoleh oleh konsumen. Maka berdasarkan hal tersebut, dapat diketahui bahwa harga jual produk tidak mempengaruhi keputusan pembelian konsumen selama obat herbal VCO dapat 
memberikan manfaat yang dibutuhkan oleh konsumen. . Harga menjadi suatu ukuran tentang mutu produk bila pembeli mengalami kesulitan dalam mengevaluasi produkproduk yang kompleks. Dalam situasi tertentu, pengguna melakukan penilaian atau menghitung-hitung tentang apa yang akan mereka peroleh sebagai balasan dari apa yang mereka berikan. Dengan demikian, harga merupakan pembatas (trade-off) untuk sejumlah benefit (nilai) yang akan diberikan oleh suatu produk (barang atau jasa) dengan sejumlah biaya yang dikaitkan dengan sejumlah biaya yang dikaitkan dengan penggunaan produk tersebut (Yazid,1999).

Pusat informasi yang menghendaki profit harus mampu menutup semua biaya yang berkaitan dengan proses memproduksi dan memasarkan suatu jasa. Selanjutnya menetapkan marjin secukupnya sehingga mampu memberikan keuntungan yang memuaskan. Yazid (1999) mengatakan bahwa harga atau biaya sebuah jasa akan mencakup harga yang bersifat moneter dan harga yang bersifat non- moneter. Harga yang bersifat moneter mempunyai peranan penting bagi bagian pemasaran untuk mengukur tingkat atau porsi penerimaan dari konsumen. Selanjutnya dikatakan bahwa, di samping itu beberapa biaya non-moneter yang mungkin diperhitungkan konsumen ketika menggunakan suatu jasa mencakup waktu, upaya bersifat fisik, biaya sensor, biaya psikologis, dan promosi.

Signifikansi Desain Kemasan Produk sebesar 0,018. signifikansi 0,018 $0.05(\alpha)$ maka $\mathrm{H}_{\mathrm{a}}$ diterima dan $\mathrm{H}_{0}$ ditolak, jadi dapat disimpulkan bahwa desain kemasan produk berpengaruh signifikan terhadap keputusan pembelian. Konsumen akan memutuskan membeli atau tidaknya suatu barang dengan memperhatikan faktor-faktor yang dianggapnya penting. Dalam membeli suatu barang atau jasa, seorang konsumen harus melewati beberapa tahapan atau proses dalam keputusan pembelian

.Keputusan pembelian adalah keputusan yang dilakukan oleh konsumen untuk membeli dan mengkonsumsi suatu produk atau jasa dalam rangka untuk memenuhi kebutuhan dan keinginannya. Adapun tahap-tahap yang dilalui konsumen dalam proses pengambilan keputusan pembelian yaitu pengenalan kebutuhan pencarian informasi, evaluasi alternatif, keputusan pembelian, perilaku setelah pembelian. Menurut penelitian, dari seluruh kegiatan penginderaan manusia, $80 \%$ adalah penginderaan melalui penglihatan atau kasatmata (visual). Karena itulah, unsur-unsur grafis dari kemasan antara lain: warna, bentuk, merek, ilustrasi, huruf dan tata letak merupakan unsur visual yang mempunyai peran terbesar dalam proses penyampaian pesan secara kasatmata (visual communication). Agar berhasil, maka penampilan sebuah kemasan harus mempunyai daya tarik. Daya tarik pada kemasan dapat digolongkan menjadi dua, yaitu daya tarik visual (estetika) dan daya tarik praktis (fungsional) (Wirya, 1999).

Untuk mengetahui signifikasi pengaruh variabel-variabel independen secara bersama-sama (simultan) terhadap variabel dependen digunakan uji F. Berikut ini merupakan tabel hasil perhitungan uji F:

\begin{tabular}{ccccccc}
\hline & Model & $\begin{array}{c}\text { Sum of } \\
\text { Squares }\end{array}$ & Df & $\begin{array}{c}\text { Mean } \\
\text { Square }\end{array}$ & F & Sig. \\
\hline \multirow{1}{1}{$\mathbf{1}$} & Regression & 2.285 & 3 & .762 & 6.640 & \multirow{\mathbf{000}^{\mathbf{a}}}{}{} \\
& Residual & 10.552 & 92 & .115 & & \\
\hline \hline & Total & 12.836 & 95 & & & \\
\hline
\end{tabular}

a. Predictors: (Constant), Desain Kemasan Produk, Citra Produk, Harga Jual Produk b. Dependent Variable: Keputusan Pembelian 
Berdasarkan uji $\mathrm{F}$ diperoleh hasil nilai signifikansi (p-value) pada uji simultan (bersama-sama) nilainya sebesar $0,000<0,05(\alpha)$, sehingga $\mathrm{H}_{0}$ ditolak dan $\mathrm{H}_{\mathrm{a}}$ diterima. Artinya citra produk, harga jual produk dan desain kemasan produk berpengaruh signifikan secara bersama-sama terhadap keputusan pembelian. Hal ini memperlihatkan bahwa para konsumen memiliki penilaian yang tinggi terhadap citra produk, harga jual produk dan desain kemasan produk dalam melakukan pembelian obat herbal VCO. Dalam melakukan keputusan pembelian terhadap obat herbal VCO, konsumen menganggap bahwa citra produk, harga jual produk dan desain kemasan produk merupakan hal penting yang harus dipertimbangkan secara bersama - sama.

Obat herbal VCO merupakan jenis produk kesehatan, di mana dalam memproduksi produk ini, perusahaan tidak boleh sembarangan karena hal ini menyangkut nyawa seseorang. Namun selain dari segi bahan baku dan proses produksi, desain kemasan merupakan salah satu hal yang tidak kalah penting. Hal ini dibuktikan dengan hasil uji secara parsial, di mana variabel desain kemasan berpengaruh terhadap keputusan pembelian. Responden menganggap bahwa desain kemasan obat herbal VCO mudah dibuka dan ditutup kembali bila akan dipakai, kemudian desain kemasan obat herbal VCO mampu melindungi produk sehingga produk aman dan tidak mudah terkontaminasi dengan udara yang kotor. Selain hal itu, responden juga menganggap bahwa kemasan obat herbal VCO memiliki desain yang unik dan menarik serta memberikan keamanan bagi konsumen untuk membuka atau menutup kemasan produk, dan yang terpenting adalah desain kemasan obat herbal VCO sudah sesuai dengan jenis produk yang dijual yaitu obat herbal

\section{KESIMPULAN}

Variabel citra produk, harga jual produk serta desain kemasan produk secara bersama-sama berpengaruh signifikan terhadap keputusan pembelian Obat Herbal VCO. Variabel citra produk dan desain kemasan produk berpengaruh signifikan secara parsial terhadap keputusan pembelian Obat Herbal VCO sedangkan untuk harga jual produk tidak berpengaruh signifikan terhadap keputusan pembelian Obat Herbal VCO.

\section{REFERENSI}

Aaker, A. David., 1996, Building Strong Brands, New York : The Free Press

Aaker, A. David., 1997, Manajemen Ekuitas Merek, Jakarta: Mitra Utama

Assauri, Sofjan, 2007. Manajemen Pemasaran. Jakarta : Rajawali Pers.

Basu, Swastha. 1997. Manajemen pemasaran Modern, Edisi ke -2. Yogyakarta: Liberty.

Basu Swastha dan Ibnu Sukotjo.(2007). Pengantar Bisnis Modern. Yogyakarta: Liberty Yogyakarta.

Buchari, Alma. (2018). Manajemen Pemasaran dan Pemasaran Jasa. Bandung: CV.Alfabeta.

Charles W. Lamb, Joseph F. Hair, Carl Mcdaniel. 2013. Pemasaran. Edisi Kedua.Jakarta :Salemba Empat.

Graham, Cateora. (2007). Pemasaran Internasional Edisi 13. Jakarta: Salemba Empat.

Ghozali, Imam.2011. Aplikasi Analisis Multivariate dengan Program SPSS. Semarang : BP Universitas Diponogoro

Gitosudarmo , Indriyo. 1999. Manajemen Pemasaran. Jakarta: BPFE. 
Goenadhi, Lydia. 2011. "Faktor-faktor Yang Mempengaruhi Perilaku Konsumen Dalam Keputusan Pembelian Mobil Toyota Avanza di Kota Banjarmasin". Jurnal Manajemen dan Akutansi, Vol. 12, No.2.

Kotler, Philip Dan Kevin Lane Keller. 2016. Manajemen Pemasaran. Edisi 15 Jilid Satu. Jakarta : Pearson

P. Angipora, Marius. 1999. Dasar-Dasar Pemasaran. Jakarta: PT. Raja Grafindo Persada.

Saladin, Djaslim, 1996, Unsur-unsur Inti Pemasaran dan Manajemen Pemasaran, Ringkasan Praktis Teori dan Disertai Tanya Jawab. Bandung :CV Mandar Maju.

Santoso, Singgih. 2014. Statistik Multivariate Konsep dan Aplikasidengan SPSS. Jakarta : PT Elex Media

Sekaran, Uma.2006. Metodologi Penelitian. Jakarta: Salemba.

Simamora, Bilson, 2008. Memenangkan Pasar dengan Pemasaran Efektif dan Profitabel. Jakarta :PT. Gramedia Pustaka Utama.

Siregar, Syofian. 2013. Metodologi Penelitian Kuantitatif. Jakarta: PT. Fajar.

Stanton, William J. 1996. Prinsip Pemasaran. Edisi ke-7. Diterjemahkan Oleh : Yohanes Lamarto. Jakarta: Penerbit Erlangga.

Sugiyono.2003. Metode Penelitian Bisnis. Cetakan Kesembilan. Bandung :CV. Alfabeta. Sugiyono.(2004). Metode Penelitian Bisnis. Cetakan keenam. Bandung : CV Alvabeta.

Sugiyono.(2008) Metode Penelitian Kuantitatif, Kualitatif dan $R \&$ D. Edisi Keempat. Bandung: CV Alfabeta.

Sutisna., 2003, Perilaku Konsumen \& Komunikasi Pemasaran, Cetakan Ketiga, Bandung: PT Remaja Posdakarya.

Wirya, Iwan. 1999. Kemasan yang Menjual. Jakarta : PT. Gramedia Pustaka Utama.

Yazid. 1999. Pemasaran Jasa, Konsep dan Implementasi. Edisi 1, Cetakan pertama. Yogyakarta :Ekonosia Fakultas Ekonomi UII. 